DOI 10.17816/transsyst201842120-128

Y. He ${ }^{1,2}$, Y.-S. Wang ${ }^{1}$, Q. Lu ${ }^{1}$, L. Zhang ${ }^{2}$, F. liang ${ }^{2}$

${ }^{1}$ College of Electrical Engineering, Zhejiang University

(Hangzhou, China)

${ }^{2}$ CRRC Zhuzhou Electric CO., LTD.

(Zhuzhou, Hunan, China)

\title{
DESIGN OF SINGLE-SIDED LINEAR INDUCTION MOTOR FOR LOW-SPEED MAGLEV VEHICLE IN 160 km/h AND VARIABLE SLIP FREQUENCY CONTROL
}

Background: The mid-low speed Maglev train adopts the single-sided linear induction motors (SLIMs) as drive part, of which design and control method has become research hotspot when the velocity is elevated from $120 \mathrm{~km} / \mathrm{h}$ to $160 \mathrm{~km} / \mathrm{h}$.

Aim: For SLIMs applied in $160 \mathrm{~km} / \mathrm{h}$ low-speed maglev train, the design scheme is introduced and then a novel variable slip frequency control method is proposed.

Methods: This control method adopts low slip frequency at start-up to produce large starting traction force and high slip frequency during high velocity area to obtain great power. The influence to the normal force is also investigated.

Results: With this method, the weight of the system can be effectively reduced and the lightweight design of SLIM is realized.

Conclusion: The novel variable slip frequency control method meets the requirement of both high starting acceleration and enough residual acceleration for $160 \mathrm{~km} / \mathrm{h}$ mid-low speed maglev train.

Keywords: Mid-low speed maglev train; linear induction motor; slip frequency; traction force; normal force

\section{INTRODUCTION}

The Changsha medium-low speed maglev line is the first commercial operation line in China and the longest one in the world. Its designed velocity is $120 \mathrm{~km} / \mathrm{h}$, and the running velocity is $100 \mathrm{~km} / \mathrm{h}$. During its two-year long commercial operation since May $6^{\text {th }}, 2016$, the longest mileage has reached $400,000 \mathrm{~km}$ and the punctuality rate has reached $99.8 \%$, which has set a good exemplary role. After the successful operation of the Changsha maglev line, the intercity transportation with higher speed class $(160 \mathrm{~km} / \mathrm{h})$ by adopting the maglev train is put on the agenda. This paper presents the design of SLIMs for mid-low speed maglev train with velocity $160 \mathrm{~km} / \mathrm{h}$ and optimizes the force performance from the aspect of control method.

\section{BASIC PARAMETERS OF MAGLEV TRAINS IN CHANGSHA LINE}

The mid-low maglev train in Changsha line consists of three coaches. Each coach covers five suspension frames, one converter and ten SLIMs. The 
basic parameters of the train and the converter are listed in Table 1. Ten SLIMs are equally divided into two groups, which are connected in parallel. To five SLIMs in one group, the phase windings connected in series are transposed to reduce the end effect, as shown in Fig. 1. As it can be seen, three phase windings are Y connected.

Table 1. Basic parameters

\begin{tabular}{|l|l|c|}
\hline \multicolumn{1}{|c|}{ Item } & \multicolumn{1}{|c|}{ Parameters } & Value \\
\hline \multirow{5}{*}{ Vehicle } & Voltage of power network /V & DC1000 1800 \\
\cline { 2 - 3 } & Track gauge /mm & 1860 \\
\cline { 2 - 3 } & Running velocity/ km/h & 100 \\
\cline { 2 - 3 } & Design velocity / km/h & 120 \\
\cline { 2 - 3 } & Coach number & 3 \\
\cline { 2 - 3 } & Vehicle mass $(\mathrm{AW} 2) / \mathrm{t}$ & 30 \\
\cline { 2 - 3 } & Starting acceleration $/ \mathrm{m} / \mathrm{s}^{2}$ & 1.0 \\
\cline { 2 - 3 } & Average acceleration/m/s $/ \mathrm{s}^{2}$ & 0.4 \\
\cline { 2 - 3 } & Residual acceleration/m/s $/ \mathrm{s}^{2}$ & 0.1 \\
\cline { 2 - 3 } & Number of suspension frame & 5 \\
\hline \multirow{5}{*}{ Converter } & Input voltage /V & DC1000 1800 \\
\cline { 2 - 3 } & Rated line voltage/ V & 1100 \\
\cline { 2 - 3 } & Rated maximum current /A & $2 \times 340$ \\
\cline { 2 - 3 } & Rated Continuous current /A & $2 \times 240$ \\
\hline
\end{tabular}

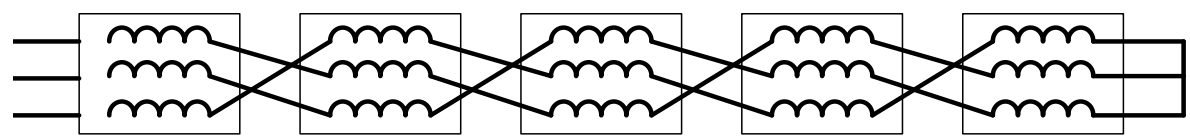

Fig. 1. The winding connection of five SLIMs in one group

\section{DESIGN ANALYSIS OF SLIMS FOR 160KM/H MAGLEV TRAIN}

\subsection{Traction force requirement}

The $160 \mathrm{~km} / \mathrm{h}$ maglev train also adopts three coaches. Its resistance force can be calculated by adopting the resistance formula of the Changsha maglev line, which includes three components as follows.

1) Magnetic resistance force

The magnetic reluctance force $D_{m}$ can be calculated by piecewise formula as follows:

$$
D_{m}=\left\{\begin{array}{ll}
3.354 W v & v<5.6 \mathrm{~m} / \mathrm{s} \\
(18.22+0.074 v) W & v>5.6 \mathrm{~m} / \mathrm{s}
\end{array},\right.
$$

where $W$ is the vehicle mass $(\mathrm{t})$, and $v$ is the running velocity $(\mathrm{m} / \mathrm{s})$.

2) Relay resistance force

The relay resistance force $D_{c}$ is almost constant, which value is $41.67 \mathrm{~N}$.

3) Aerodynamic resistance force 
The aerodynamic resistance force $D_{a}$ mainly depends on the velocity and coach number.

$$
D_{a}=(1.652+0.572 N) v^{2},
$$

where $N$ is the coach number.

The total resistance force $D$ is the sum of three former components. The traction force $F$ is obtained through the total resistance force and acceleration.

$$
F=D_{m}+D_{c}+D_{a}+W a=D+W a,
$$

where $a$ is the acceleration.

When the running velocity is increased from $120 \mathrm{~km} / \mathrm{h}$ to $160 \mathrm{~km} / \mathrm{h}$ and the minimum residual acceleration is maintained at $0.1 \mathrm{~m} / \mathrm{s}^{2}$, the power increases by $66.7 \%$, as shown in Table 2 .

Table 2. Power requirement of the $160 \mathrm{~km} / \mathrm{h}$ maglev train

\begin{tabular}{|l|c|c|}
\hline Design velocity & $120 \mathrm{~km} / \mathrm{h}$ & $160 \mathrm{~km} / \mathrm{h}$ \\
\hline Vehicle mass / t & 30 & 32 \\
\hline Total resistance force / $\mathrm{kN}$ & 5.65 & 8.76 \\
\hline Traction force/per motor $/ \mathrm{kg}$ & 50 & 62.5 \\
\hline Vehicle power $/ \mathrm{kW}$ & 490 & 816.7 \\
\hline
\end{tabular}

\subsection{Basic parameters of traction system}

As the vehicle power increases, the number of converters or the capacity of single IGBT needs to be increased. Obviously, it is more economical to increase the IGBT capacity. The maximum current of available IGBT with matching voltage level is $2 \times 450 \mathrm{~A}$. Therefore, the power can increase by $32 \%$ in comparison with the Changsha lines with IGBT of $2 \times 340$ A maximum current.

Since the IGBT capacity does not increase by $66.7 \%$, it means the starting traction force should be reduced or the volume should be improved to reduce the starting current. According to the consultation with the OEM, the length of SLIM can be increased from $1,820 \mathrm{~mm}$ to $2,020 \mathrm{~mm}$. In addition, the starting traction force is reduced since the starting acceleration is changed from $1.0 \mathrm{~m} / \mathrm{s}^{2}$ to $0.8 \mathrm{~m} / \mathrm{s}^{2}$, which meets the start acceleration of the general intercity vehicle.

\subsection{Vehicle configuration}

The number of modules per train and the selection between available mode (five-string double-parallel) and new mode (two-string five-parallel mode) need to be determined. The most economical and reliable method is to keep the original vehicle structure.

\subsection{Design requirements}

Based on the foundation of the Changsha maglev line, the main design requirements of the $160 \mathrm{~km} / \mathrm{h}$ maglev train are listed in Table 3 . 
Table 3. Power requirement of the $160 \mathrm{~km} / \mathrm{h}$ maglev train

\begin{tabular}{|l|c|}
\hline Vehicle mass (AW2) / t & 32 \\
\hline Mechanical air gap of SLIMs / mm & 12 \\
\hline Length of the SLIM / mm & 2020 \\
\hline Converter input current / A & $2 \times 450$ \\
\hline Maximum vehicle velocity / $(\mathrm{km} / \mathrm{h})$ & 160 \\
\hline Average starting acceleration $(0 \sim 70 \mathrm{~km} / \mathrm{h}) /\left(\mathrm{m} / \mathrm{s}^{2}\right)$ & $\geq 0.8$ \\
\hline Average acceleration $(0-160 \mathrm{~km} / \mathrm{h}) /\left(\mathrm{m} / \mathrm{s}^{2}\right)$ & $\geq 0.4$ \\
\hline Residual acceleration $(160 \mathrm{~km} / \mathrm{h}) /\left(\mathrm{m} / \mathrm{s}^{2}\right)$ & $\geq 0.1$ \\
\hline
\end{tabular}

\section{THE DESIGN OF SLIMS}

\subsection{Basic parameters}

Based on the former analysis, the SLIMs, JX170, applied in the $160 \mathrm{~km} / \mathrm{h}$ maglev train is designed, shown in Fig. 2. The train has the original five-module structure and SLIMs per coach with five strings two parallel connection mode. The motor basic parameters comparison with SLIM of the Changsha maglev line, JX130, are listed in Table 4.

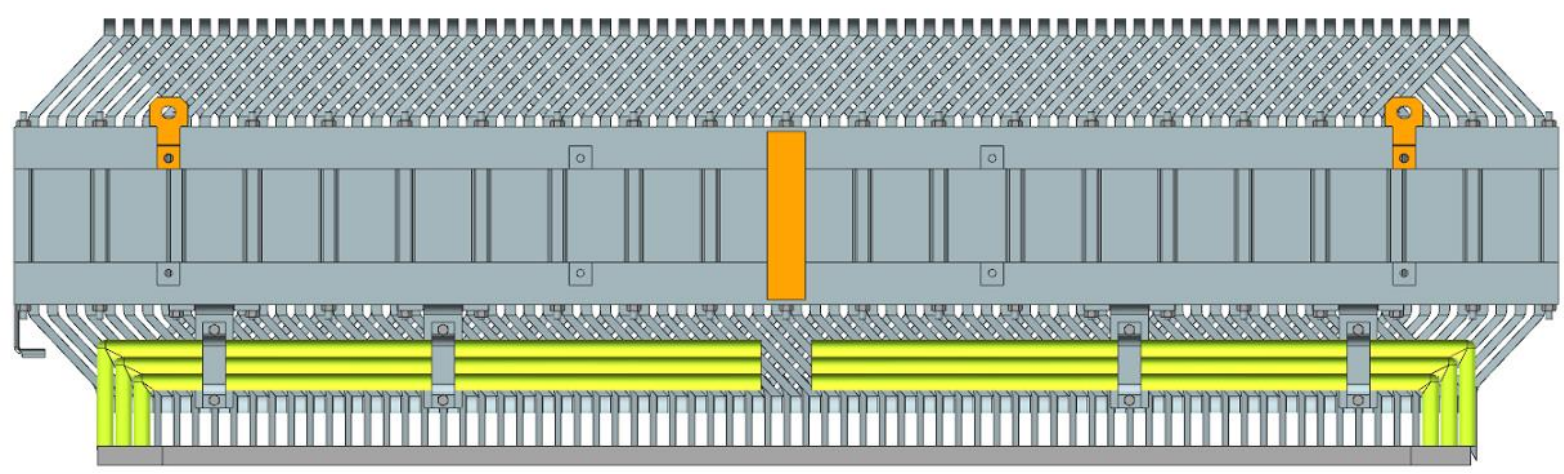

Fig. 2. JX170 SLIM

Table 4. Basic parameters comparison of two SLIMs

\begin{tabular}{|l|c|c|}
\hline SLIM type & JX130 & JX170 \\
\hline Rated voltage/V & \multicolumn{2}{|c|}{220} \\
\hline Pole number & \multicolumn{2}{|c|}{8} \\
\hline Thickness of the aluminum plate/mm & \multicolumn{2}{|c|}{220} \\
\hline Width of F-shaped rail/mm & 340 & 450 \\
\hline Starting current/A & 240 & 360 \\
\hline Rated current/A & 3,234 & 2,764 \\
\hline Starting force/N & 200 & 215 \\
\hline Primary mass/kg & 202.5 & 225 \\
\hline Pole pitch/mm & 1,820 & 2,020 \\
\hline Primary length/mm & 13 & 12 \\
\hline Air gap/mm & & \\
\hline
\end{tabular}

\subsection{Control settings}

The control method of the SLIMs for magnetic levitation trains is different from that of the induction traction motor for subways. First, for simple 
control, the SLIMs for magnetic levitation trains generally use constant current and constant slip frequency control method. Second, SLIMs must consider the effect of the normal force. Therefore, the suitable slip frequency $f_{2}$ is important parameter for SLIMs.

With the equivalent circuit of an induction motor, the influence of slip frequency on SLIMs performance can be analyzed.

Normally, constant current control method is used during start-up. Their relationship is shown as follow. Apparently, the traction force is inversely proportional to the slip frequency, $f_{2}$.

$$
F_{x}=\frac{m R_{2}^{\prime}\left(I_{2}^{\prime}\right)^{2}}{2 \pi f_{1} s}=\frac{m R_{2}^{\prime}\left(I_{2}^{\prime}\right)^{2}}{2 \pi f_{2}},
$$

when the starting acceleration of the train reaches $0.8 \mathrm{~m} / \mathrm{s}^{2}$, the traction force per SLIM is $2567 \mathrm{~N}$. Under this condition, the maximum slip frequency $f_{2}$ should be 15.7 Hz. If adopting the control method of constant slip frequency, the traction force at maximum velocity is $710 \mathrm{~N}$ per SLIM and the residual acceleration of the train at $160 \mathrm{~km} / \mathrm{h}$ is $0.13 \mathrm{~m} / \mathrm{s}^{2}$.

At high velocity, the SLIM already adopts full voltage. The SLIM torqueslip curve is similar with induction-machine. As can be seen from Fig. 3, during the motor region, the higher the $f_{2}$, the higher the slip, and the larger the traction force is.

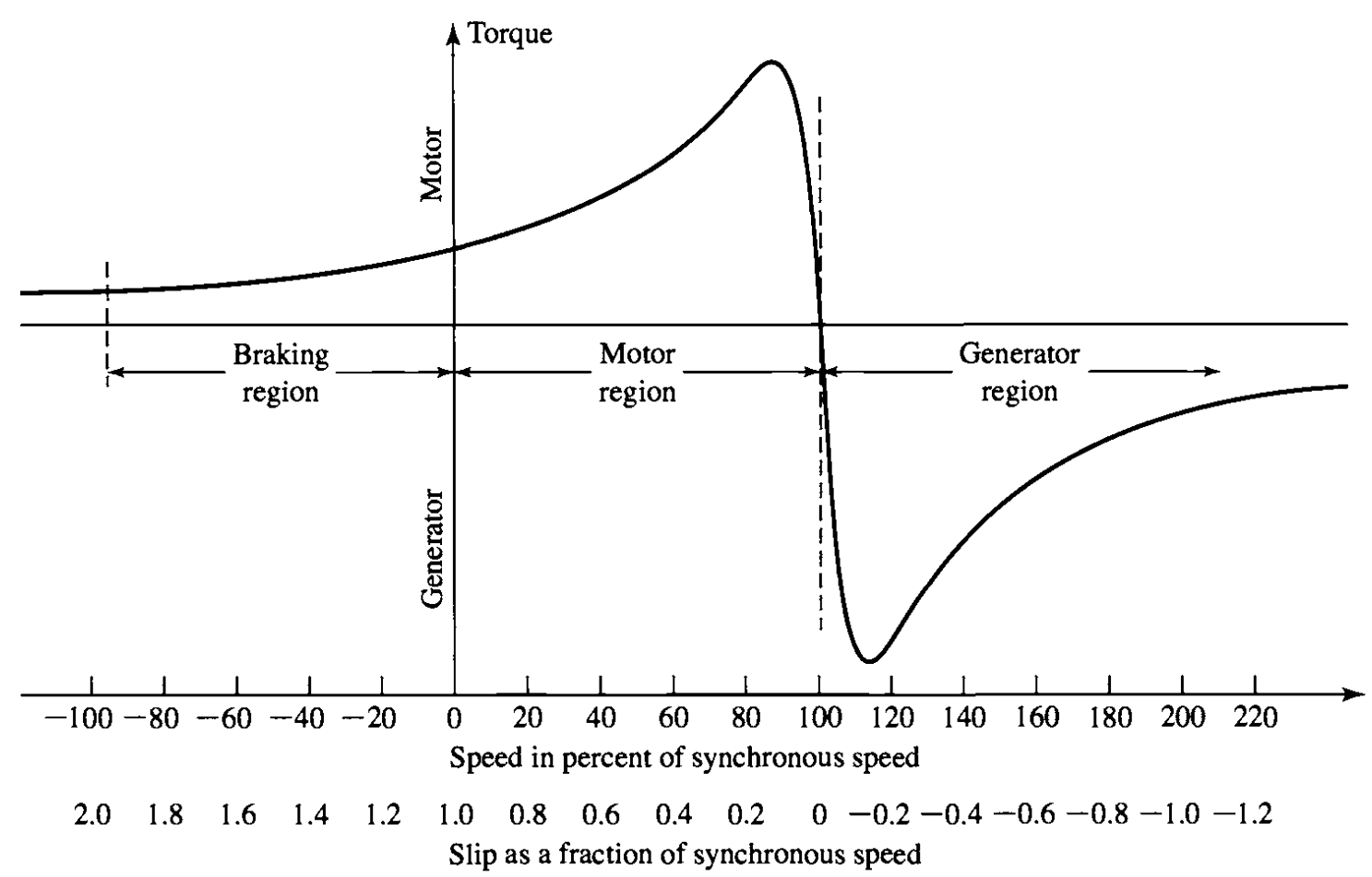

Fig. 3. Induction-machine torque-slip curve during whole operation area 
When the required remaining acceleration is $0.1 \mathrm{~m} / \mathrm{s}^{2}$, the traction force per SLIM is $612 \mathrm{~N}$. To this required traction force, the minimum slip frequency f2 is $13.7 \mathrm{~Hz}$. If keeping this slip frequency as constant value, the starting traction force can be increased up to $2,764 \mathrm{~kg}$.

In order to verify the former traction force at start-up and maximum velocity, the 3D model of JX170 is erected by 3D FEM. For slip frequency 13.7 Hz, the calculated thrust force at start-up is 2,720 N. For slip frequency $15.7 \mathrm{~Hz}$, the calculated thrust force at maximum velocity is $753 \mathrm{~N}$. Compared with the predicted results of equivalent circuit method, the errors are $44 \mathrm{~N}$ and $43 \mathrm{~N}$ under two conditions respectively. Apparently, the results of equivalent circuit method are reasonable.

Therefore, the slip frequency should between 13.7 to $15.7 \mathrm{~Hz}$. The traction characteristics are shown in Fig. 4 with the slip frequency values of $13.7 \mathrm{~Hz}$ and $15.7 \mathrm{~Hz}$, respectively. And the normal force is considered acceptable.

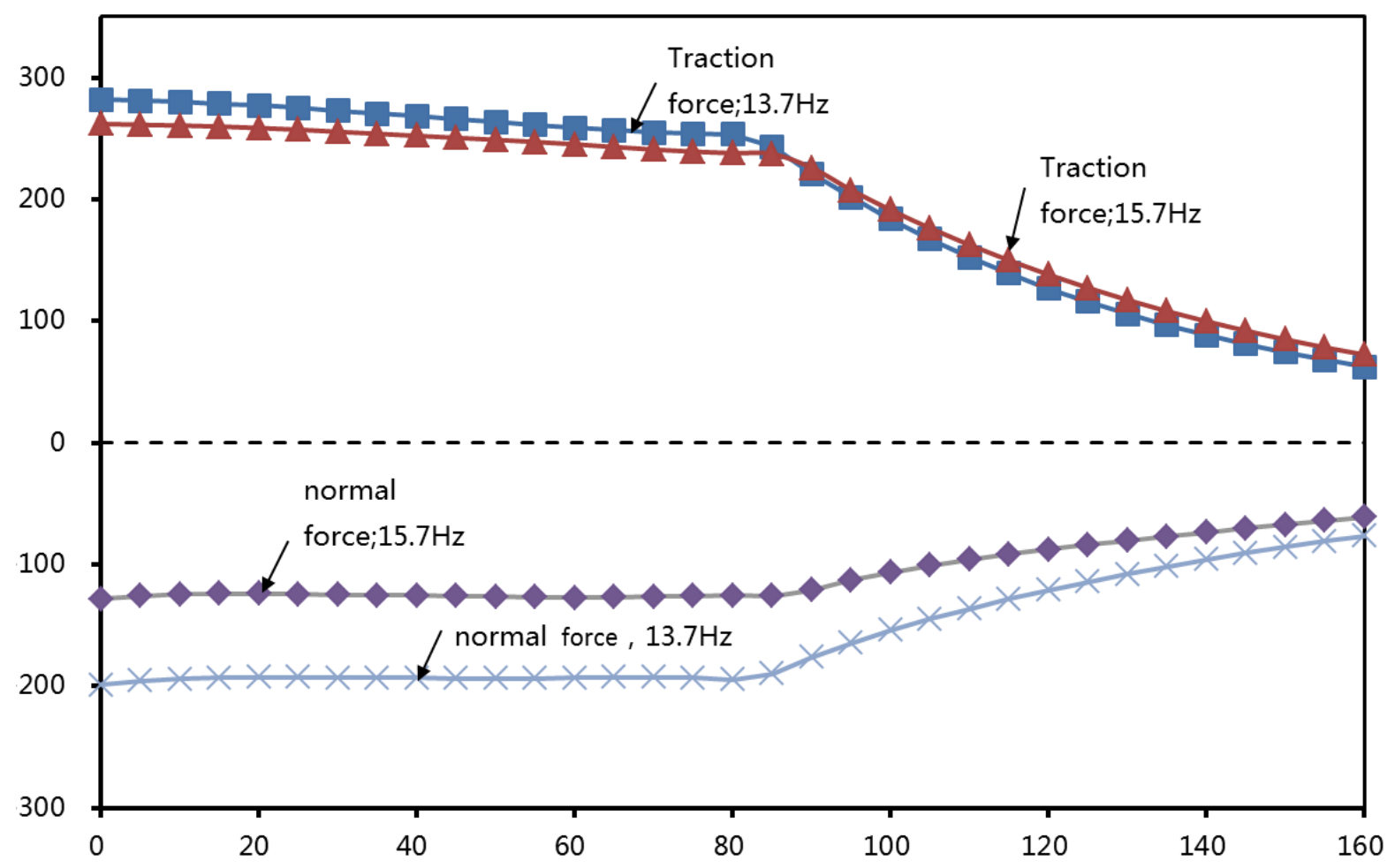

Fig.4. The traction characteristics with the constant current slip frequency $13.7 \mathrm{~Hz}$ and $15.7 \mathrm{~Hz}$

\section{VARIABLE SLIP FREQUENCY CONTROL METHOD}

From former analysis, it can be deduced that the SLIM performance of high velocity or low velocity is inevitably sacrificed when a constant current and constant slip control method is applied. However, this can be avoided if variable 
slip control method is adopted in SLIMs. Since they start with a lower starting frequency to produce larger starting traction force, and operate with higher slip frequency to obtain larger power at high velocity area, the capacity can be fully utilized.

To JX170 SLIMs, at the low velocity, the slip frequency $13.7 \mathrm{~Hz}$ is adopted to increase the starting traction force. At high velocity, the slip frequency is increased to $17.2 \mathrm{~Hz}$, which increases the traction force. The traction characteristics are shown in Fig. 5. This method considers the starting acceleration and the residual acceleration of high velocity, which increases the starting capability and reduces the starting distance.

When the variable slip frequency control method is used, the traction characteristics of the train can only be within the envelope to meet a certain overload capacity. Moreover, it should not be far away from the envelope to make full use of motor capability as shown Fig. 5

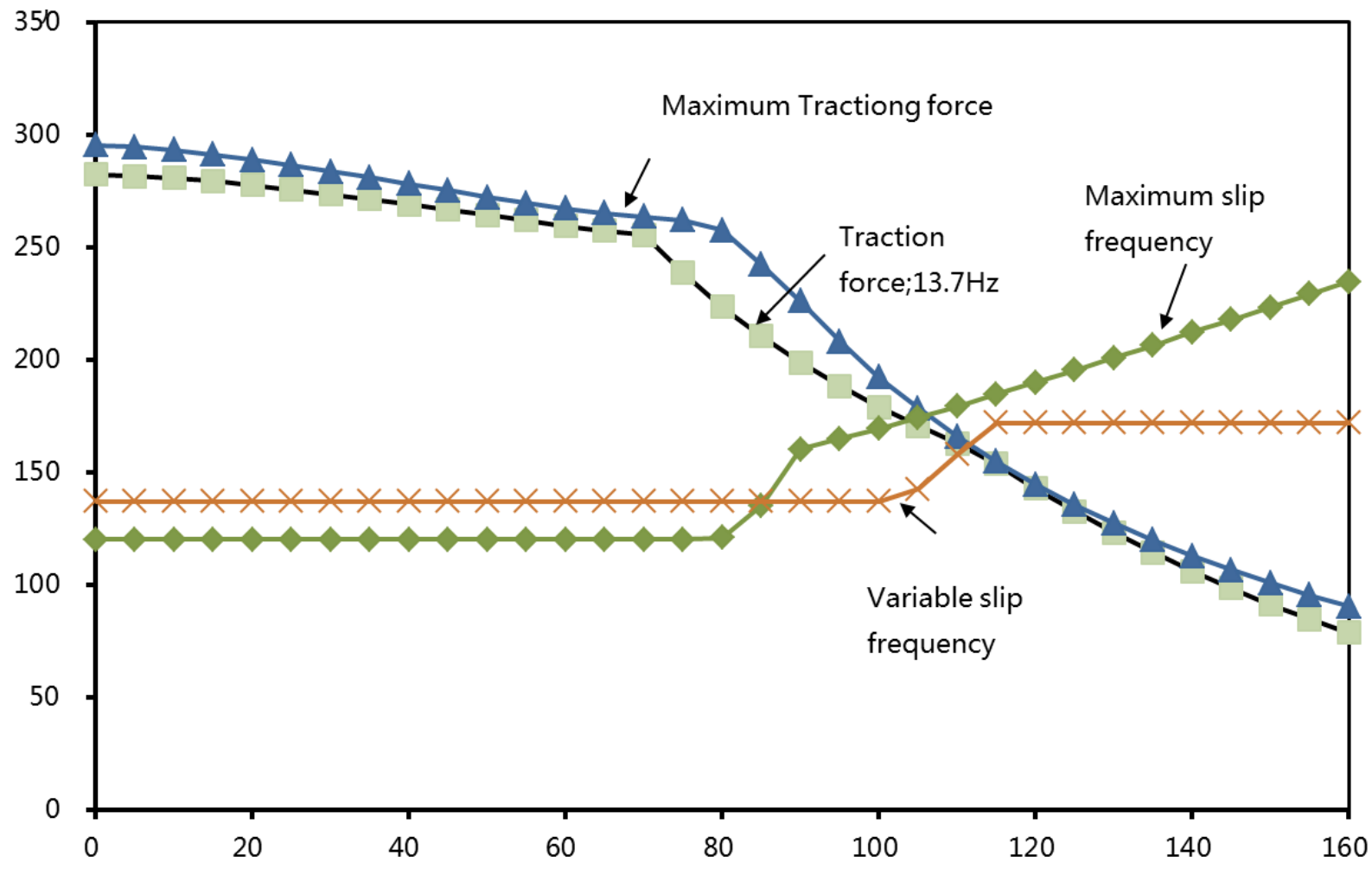

Fig. 5. Maximum traction force curve

With slip frequency change from $13.7 \mathrm{~Hz}$ to $17.2 \mathrm{~Hz}$, the residual acceleration is increased by $70 \%$ compared with the constant slip frequency control method, and then the acceleration time is reduced by $17 \%$ and the acceleration distance is reduced by $22 \%$, as shown in Table 5 . 
Table 5. Starting performance of variable slip frequency control method

\begin{tabular}{|l|c|c|c|}
\hline \multicolumn{1}{|c|}{ Control method } & $\begin{array}{c}\text { Constant slip } \\
\text { frequency }\end{array}$ & $\begin{array}{c}\text { Variable slip } \\
\text { frequency }\end{array}$ & Change rate \\
\hline Start-up frequency $/ \mathrm{Hz}$ & 13.70 & 13.7 & \\
\hline Start acceleration $/\left(\mathrm{m} / \mathrm{s}^{2}\right)$ & 0.86 & 0.86 & \\
\hline End-up slip frequency $/ \mathrm{Hz}$ & 13.7 & 17.2 & \\
\hline Residual acceleration $/\left(\mathrm{m} / \mathrm{s}^{2}\right)$ & 0.10 & 0.17 & $+70 \%$ \\
\hline Average acceleration $/\left(\mathrm{m} / \mathrm{s}^{2}\right)$ & 0.40 & 0.48 & $+20 \%$ \\
\hline Acceleration time $/ \mathrm{s}$ & 110.6 & 91.7 & $-17 \%$ \\
\hline Acceleration distance $/ \mathrm{m}$ & 3,369 & 2,613 & $-22 \%$ \\
\hline
\end{tabular}

\section{CONCLUSION}

This paper presents the design of SLIMs for mid-low speed maglev train with velocity $160 \mathrm{~km} / \mathrm{h}$, which meets the performance requirement of the $160 \mathrm{~km} / \mathrm{h}$ mid-low speed maglev train. It has the characteristics of derivative design and economical reliability.

It also proposes a variable slip frequency control method for the SLIM. With a lower slip frequency at start-up, the SLIM has a larger starting traction force. At high velocity, a higher slip frequency is used, and a larger motor power is realized. The train acceleration performance is optimized without additional space, mass and cost. This proposed control method can also be applied to other maglev trains driven by SLIMs.

\section{References}

1. Yan G L. The linear motor powered transportation development and application in China Proc. IEEE. 2009;97(11):1872-1880. doi: 10.1109/JPROC.2009.2030245

2. Gieras JF, Dawson GE, Eastham AR. Performance calculation for single-sided linear induction motors with a double-layer reaction rail under constant current excitation. IEEE Trans. Magn. 1986;1M-22(1):54-62.

3. Im DH, Park SC, Im JW. Design of single-sided linear induction motor using the finite element method and SUMT. IEEE Trans. Magn. 1993;29(2):1762-1766.

4. Dawson G, Easthma AR, Gieras JF, Ong R, Ananthasivam K. Design of linear induction drives by field analysis and finite-element techniques. IEEE Trans. Ind. Appl. 1986;IA-22(5):865-873.

5. Ye YY. The Theory and Application of Linear Motor. Beijing, China: Mech. Ind. Press, Jun. 2000.

6. Ham SH, Lee SG, Kim KS, Cho SY, Jin CS, Lee J. Study on reduction of transverse edge effect of single-sided linear induction motor for transportation system. Proc. Int. Conf. Electr. Mach. Syst., Tokyo, Japan, Nov. 2009, p. 1-4.

7. Lv G, Li Q, Liu ZM, Fan Y, Li GG. The analytical calculation of the thrust and normal force and force analyses for linear induction motor. Proc. 9th Int. Conf. Sig. Process., Beijing, China, Dec. 2008, p. 2795-2799.

8. Gieras JF, Dawson GE, Eastham AR. A new longitudinal end effect factor for linear induction motors. IEEE Trans. Energy Convers. 1987;EC-2(1):152-159.

9. Lu JY, Ma WM. Research on end effect of linear induction machine for high-speed 
industrial transportation. IEEE Trans. Plasma Sci. 2011;39(1):116-120. doi: 10.1109/TPS.2010.2085089

10. Kim D-K, Kwon B-I. A novel equivalent circuit model of linear induction motor based on finite element analysis and its coupling with external circuits. IEEE Trans. Magn. 2006;42(5):3407-3409. doi: 10.13334/j.0258-8013.pcsee.2015.15.026

11. Yamaguchi T, Kawase Y, Yoshida M, Saito Y, Ohdachi Y. 3-D finite element analysis of a linear induction motor. IEEE Trans. Magn. 2001;1.37(5):3668-36741.

12. Lv G, Zeng D, Zhou T, Liu Z. Investigation of forces and secondary losses in linear induction motor with the solid and laminated back iron secondary for metro. IEEE Trans. Ind. Electron. 2017;64(6):4382-4390. doi: 10.1109/TIE.2016.2565442

13. Lu Q, Li Y, Ye Y, Zhu ZQ. Investigation of forces in linear induction motor under different slip frequency for low-speed maglev application. IEEE Trans. Energy Convers, 2013;28(1):45-153. doi: 10.13334/j.0258-8013.pcsee.2015.15.026

Information about the authors:

Yunfeng He, Ph.D, senior engineer;

ORCID: 0000-0002-9951-3919;

E-mail: heyunfeng@crrcelectric.com

You-Sheng Wang, bachelor, Professor;

ORCID: 0000-0002-8081-4957;

E-mail: eewangys@zju.edu.cn

Qinfen Lu, Ph.D, Professor;

ORCID0000-0002-3452-5564;

E-mail: luqinfen@zju.edu.cn

Lei Zhang, master, engineer;

ORCID: 0000-0003-0840-9401;

E-mail: zhanglei@crrcelectric.com

Fang Liang, master, engineer;

ORCID: 0000-0001-8874-9208;

E-mail: fangliang@crrcelectric.com

\section{To cite this article:}

He Y, Wang Y-S, Lu Q, et al. Design of Single-Sided Linear Induction Motor for Low-Speed Maglev Vehicle in $160 \mathrm{~km} / \mathrm{h}$ and Variable Slip Frequency Control. Transportation Systems and Technology. 2018;4(2):120-128. DOI: 10.17816/transsyst201842120-128. 